\title{
CORRESPONDENCE
}

\author{
Reform of the GMC \\ $S$ A A Gilani, FRCS. \\ The Progestasert and ectopic \\ pregnancy \\ R Snowden, PHD. \\ Renovating acute wards in older \\ hospitals \\ Sir Francis Avery Jones, FRCP. \\ Structure of vocational training \\ programmes \\ M A Varnam, MRCGP \\ Diet and heart disease \\ H M Sinclair, FRCP; Surgeon Captain \\ $T$ L Cleave, FRCP. \\ Coronary heart disease and short \\ stature \\ L R Jenkins, LMSSA . . . . . . . . . . . 1603 \\ Incidence and mortality of acute \\ pancreatitis \\ D F Graham, FRCS; J E Trapnell, FRCS . \\ Outpatient chemotherapy for breast \\ cancer \\ L A Price, MRCP and J H Goldie, FRCP(c). . 1603
}

J Z Adami.................. 1604

Plight of Maltese medical students

L J German, FrCOG. . . . . . . . . . . . . . . . . . . 1604

Glucagon and secretin in

aspirin-induced erosive gastritis

H A Carmichael, MRCP, and others. . . . . 1604

rolonged malaria prophylaxis

W Peters, MD.

Medical moralising

C G Scorer, FRCS.

Bromocriptine and uterine neoplasia

$\mathrm{R}$ W Griffith................... 1605

"Curing" minor illness in general

practice

J E Backhouse, MRCGP; A C M Inwald,

MRCGP $\ldots \ldots \ldots \ldots \ldots \ldots \ldots \ldots \ldots \ldots$

Scattering of starch powder

F G T Hayhoe, FRCP, and R J Flemans,

AIST ................... 1606

Offensive self-description?

R S MacDonald, MRCP............ 1606
Head-worn hearing aids

J W Stephenson, FRCS. . . . . . . . . . . . . 1606

Emergency in emergency departments

K C Easton, FRCGP............... 1606

What price the ambulance?

L Porter $\ldots . \ldots . \ldots . \ldots 16$

Raising the wind for practice premises

P J Barber, MB . . . . . . . . . . . . . . . . 1607

Clinical competence and the

Ombudsman

J Siegler, FRCS; R R Drury, MB . . . . . . . . 1607

Medical salaries

D W Young, MRCP. . . . . . . . . . . . 1607

Distinction awards

H Jacobs, MRCPSYCH. . . . . . . . . . . . . . 1607

Points from letters Vertigo in children (Patricia M Sarter; B E Schlesinger); Vertigo and the pill (H Maclean); Dietary fibre and coronary disease (A D Robertson); Why smoke a pipe? (Jane $M$ Bateman); Oust the louse (A J Singer); "Curing" minor illness in general practice (K B Thomas); Computed tomography and the NHS (P H Lord); GPs' self-respect (D C Wilkins)....... 1608
Correspondents are urged to write briefly so that readers may be offered as wide a selection of letters as possible. So many are being received that the omission of some is inevitable. Letters should be signed personally by all their authors.

\section{Reform of the GMC}

SIR,-Please accept my congratulations for your very prompt and to-the-point leading article on this subject (26 November, p 1369). I wholeheartedly agree with the comments that you have made and agree with you that "the inadequacies of the minority of recent arrivals should not rub off on to the majority of well-qualified immigrants," and I welcome any suitable and just method of assessing the standards of overseas doctors before entry to Britain and the National Health Service.

I agree with you that the Bill is very negative in its present form as far as overseas doctors are concerned. Temporary registration should be abolished and a more flexible system of registration adopted. After the TRAB test overseas doctors should be able to pursue their training and career objectives without the inconvenience or hindrance that results from the system of temporary registration and should also be able to progress to full registration after some time in the light of their experience obtained in this country. They should not be required to take another examination to obtain full registration. I would have thought that the Government would have welcomed the proposal and included it in the Bill, which is meant to do away with anomalies of the past system, but it has not done so, at least for the time being. As you say, it is still not too late to include this clause in the present Bill, and I only hope and pray that the Government is able to do it; otherwise overseas doctors are going to be terribly disappointed.

On the question of specialist registration and free interchange between Britain and EEC
I would like to see overseas doctors who have obtained specialist training and postgraduate qualifications given the same kind of right of freedom, irrespective of their primary qualifications, as long as they are British nationals and hold full registration certificates from the GMC. This would be just and fair.

One other thing which you have not mentioned in your article is the plight of 150 or so Pakistani doctors who were affected as a result of the Pakistan Act 1973. These doctors had already entered the United Kingdom and were working in preregistration and other jobs and progressing satisfactorily towards obtaining full registration. They hold recognised qualifications and would have been eligible for full registration but for the Pakistan Act. The Government had every right to enact the legislation because Pakistan had opted out of the Commonwealth. It was not possible to continue reciprocal arrangements of medical qualifications. But I would have thought that the Government could have taken a kinder view and reserved the rights of those already entered this country who were already doing the required jobs to obtain full registration-as indeed it has done in its present Bill with regard to the Irish doctors. The Medical Bill provides for ending the agreement in 1927 between the United Kingdom and the Republic of Ireland under which Irish doctors are appointed to the GMC and there are reciprocal arrangements for the mutual recognition of Irish and British qualifications. The Government intends to terminate this agreement with the full cooperation of the Irish Government. When it ends the GMC will operate on a United Kingdom basis rather than on a British Isles basis as at present. However, the rights of doctors who are already qualified and of people who are embarking on their medical studies when the agreement ends will be preserved. The same kind of treatment can be extended to the Pakistanis who were affected by the Pakistan Act.

The Department of Health and Social Security has already given the overseas doctors the impression that they understand their problems, and would like to help solve them. Isn't the time now ?

One final comment which I would wish recorded, and that is on the positive aspect of the Bill. The areas which it has covered are dealt with beautifully and no doubt it is an excellent piece of legislation and will help the GMC discharge its functions better and more effectively.

S A A GILANI General Secretary, Overseas Doctors' Association
in the UK

Manchester

\section{The Progestasert and ectopic pregnancy}

SIR,-The company responsible for the distribution of the Progestasert intrauterine contraceptive device (IUD) in the UK (May and Baker Ltd) has indicated in recent press statements that it is ceasing to recommend the use of the device because of doubts concerning the reported incidence of ectopic pregnancy in trials conducted overseas among women wearing this device. The action taken resulted from the statement of comparative data analysis carried out by this unit culminating in the evidence I now wish to share with members of the medical profession who may be fitting, or considering fitting, this device. The staff of May and Baker have acted openly 
throughout this period of inquiry and have co-operated to the fullest extent with the unit.

To obtain information concerning the incidence of ectopic pregnancy it is necessary to use studies which have a very large IUD data base. The pregnancy rate among IUD users is rarely above 4.0 per 100 users per year and the ectopic pregnancy rate has been estimated as being between 1 in 20 and 1 in 30 of these pregnancies. This unit has a very large data base relating to approximately 45000 IUD fittings describing the IUDs commonly available in the UK. The Progestasert is a relatively new device and only one large-scale study has been reported. ${ }^{1}$ Another independent study of the Progestasert is currently under way under the auspices of WHO, but this study is relatively small in size. No other large-scale studies of the Progestasert have been reported in Britain or elsewhere.

On examining more carefully the data presented in the Alza report ${ }^{1}$ I discovered that the incidence of extrauterine pregnancy among women using the Progestasert was reported as being $21 \%$ of all pregnancies. This crude figure of 1 in 5 pregnancies appeared to be much higher than that reported for other IUDs in other studies. The Alza report was made available to the American Food and Drug Administration (FDA) and the UK Committee on the Safety of Medicines, and neither organisation appeared to query this statistic. This finding could easily be missed on a first reading of the report (as I did myself), perhaps owing to the way in which the data have been presented in the report. There is a mixture of the three ways of presenting such information: the proportion of pregnancies reported, the rate per 100 women, and the more involved expected $v$ achieved rate per 1000 conceptions.

On realising the importance of this finding I analysed the data relating to all IUD pregnancies held at the unit according to these three systems of analysis. The results are contained in the accompanying table. Notice that I have restricted the pregnancies for the "inert" and "copper" devices to the first 12 months of use, as this gives a fairer comparison with the Progestasert, which is routinely removed at the end of 12 months.

Among the population selected in the Alza study a rate of 0.4 ectopic pregnancies per 100 woman-years of observation was discovered-I compared this rate among other releasing) devices and found the rate to be about 0.06 per 100 woman-years. This shows a difference in magnitude of between 6 and 7 times when comparing the Progestasert with other devices. The question is then asked, women wearing other (non-progesterone-

can we really compare these two sets of data? My contention is that while we cannot be certain of a causal relationship between use of the Progestasert and an increased incidence of ectopic pregnancy on this type of evidence, we can say that a case has been made for further detailed investigation. It is pending the results of this investigation that the distributors have voluntarily ceased to recommend its use. If it can be shown that the population selected from the Alza study has an unusually high incidence of ectopic pregnancy compared with the UK population, then this will partly explain the difference in rates between the devices described in the table. But the differences are very large and suggest the need for a full and careful investigation.

The unit is not in a position to provide evidence which confirms the cause of ectopic pregnancy among IUD users, but we can say that women who become pregnant when wearing an IUD are more likely to have an ectopic pregnancy than those not wearing an IUD. For the first time we have evidence that the type of IUD may be relating to an increased incidence.

It should be emphasised that the company responsible for distributing the device in the $\mathrm{UK}$ was as unaware of this problem as those who first read the report describing the original trial. It is only as the result of subsequent detailed examination of the data that the increased ectopic pregnancy rate has come to light. I understand that the submission to the licensing authority in the UK was based on the data produced by Alza for the FDA and a product licence was granted before the UK distributor was appointed.

In order to obtain some evidence concerning the possible incidence of ectopic pregnancy among Progestasert users in the UK I would be very pleased to receive any relevant information from those who have fitted this device since its introduction in January 1977.

\section{ROBERT SNOWDEN} Project Director,
Family Planning Research Unit

Department of Sociology,

\section{Alza Corporation, The Progestasert-Progesterone
Uterine Therapeutic System. A Product Profile, 1976.}

\section{Renovating acute wards in older} hospitals

SIR,-The recent special allocation of $£ 55 \mathrm{~m}$ over 18 months to the NHS towards the urgent task of renovation and maintenance ${ }^{1}$ was most welcome news. Mr David Ennals intends to help particularly the long-stay

Ectopic pregnancies

\begin{tabular}{|c|c|c|c|}
\hline & $\begin{array}{c}\text { Based on } \\
\text { conception rate } \\
\text { (Tietze method) }\end{array}$ & $\begin{array}{l}\text { Per } 100 \text { women } \\
\text { (Pearl Index) }\end{array}$ & $\begin{array}{c}\text { Ectopic } \\
\text { pregnancies as a } \\
\text { proportion of } \\
\text { pregnancies } \\
\text { occurring }\end{array}$ \\
\hline All Lippes Loop IUDs ( 4 sizes $(n=6872)$ & $\begin{array}{l}\text { Expected } 34-51 \\
\text { Observed } 3 \\
\text { Reduction of } 91-94^{\circ}\end{array}$ & 0.06 & $\begin{array}{l}4 \cdot 2^{\circ} \\
(1: 24)^{\prime \prime}\end{array}$ \\
\hline $\begin{array}{l}\text { Copper-carrying IUDs }(\mathrm{Cu}-7 \text { and } \mathrm{Cu}-\mathrm{T}) \\
(\mathrm{n}=9596)\end{array}$ & $\begin{array}{l}\text { Expected } 45-68 \\
\text { Observed } 2 \\
\text { Reduction of } 96-97^{\circ},\end{array}$ & 0.05 & $\begin{array}{l}1.7 \% \\
(1: 57)\end{array}$ \\
\hline $\begin{array}{l}\text { Progesterone-releasing IUD (Progestasert) } \\
(n=6813)\end{array}$ & $\begin{array}{l}\text { Expected } 39-58 \\
\text { Observed } 17 \\
\text { Reduction of } 56-71^{\circ},\end{array}$ & 0.37 & $\begin{array}{l}21^{\circ} \\
(1: 5)\end{array}$ \\
\hline
\end{tabular}

All the rates given above are based on the first year of use only.

Source of data for all devices other than the Progestasert-Family Planning Research Unit, IUD data bank. The Progestasert data are extracted from the Alza report.' patients in geriatric and mental care units. May I make a plea for some of this money to go towards upgrading acute wards in our main district general hospitals, many of which have suffered from planning blight ever since the hospital rebuilding plan began in 1960 ?

Many of these hospitals, built 75-100 years ago, are likely to remain in service for a long time yet, and particularly in large conurbations to remain the backbone of the hospital service. The new hospitals which have been built are proving expensive to run and now drain the resources of their neighbours. Fortunately the solidly built older hospitals can be refitted relatively inexpensively. The muchneeded toilets and extra rooms can be added without loss of the homely, friendly atmosphere which tends to be missing from our newer hospitals. Most short-stay patients in acute wards tolerate the inadequate conditions, appreciating the excellence of the nursing and medical care, but a few may strongly object. It is the ward staff who are being constantly frustrated and irritated by trying to privde present-day medicine under substandard conditions.

I believe the time has come to abandon the pretence that every district hospital in the country is going to be rebuilt in measurable time. It would be a wonderful help to morale if the Secretary of State sponsored a plan to provide reasonable basic conditions for the principal older district general hospitals which carry such a heavy load of acute work. For the next decade refitting should have priority over building new "nucleus" hospitals. A "doomsday"-type survey, as was done for schools, would quickly assess the magnitude and regional variations of the problem. Of course it must run pari passu with the upgrading of long-stay units. An imaginative plan might achieve considerable financial support both from the public and from charitable foundations.

F AVERy JoNes

London W1

' Hansard, House of Commons, 4 November 1977, col 264.

\section{Structure of vocational training programmes}

SIR,-I would like to thank you for publishing Dr Conrad Harris's stimulating Personal View (12 November, $p$ 1282). His vision of a change in the way in which a three-year vocational training programme is balanced between hospital and general practice is, I am sure, shared by many of those who actually run such programmes. The stumbling block is the Department of Health and Social Security, which has repeatedly refused to fund more than 12 months as a trainee general practitioner. If this hurdle could be overcome, then schemes up and down the country could experiment with release from general practice to hospital in order to increase the trainees' knowledge and skills in clinical medicine. However, I suspect that even without any stumbling block there would always need to be some period of experience in a hospital residency at senior house officer level. This is because the expected benefits from a post in general medicine are unlikely to be achieved by sessional release from general practice.

I should like to differ from Dr Harris on just one point that he makes in his article. This is in relation to the half-day release programme that is an integral part of any vocational train- 